DOI: 10.20472/IAC.2018.040.061

\author{
NANTARAT TANGVITOONTHAM \\ Faculty of Economics, Srinakharinwirot University, Thailand
}

\title{
VALUE OF PUBLIC GOODS GENERATED BY NATIONAL SPORT TRAINING CENTER (NSTC): THE CVM APPROACH
}

\begin{abstract}
:
This research objects to value of a public investment project, National Sport Training Center (NSTC), which generates valuable public goods and positive externalities, though such benefits are difficult to measure. It specifically describes the use of the Contingent Valuation Method (CVM) to conduct such surveys and to analyze the data to measure the benefits produced by sports public goods. The survey showed the feasibility of using the CVM to estimate willingness-to-pay for sports public goods. Also, to answered the question of how much sports are worth since the government has subsidized the construction the NSTC. The valuation of public goods are examined. The data and analysis indicate that NSTC can produce public goods such as national pride and spirit and the value of those public goods may be substantial. The study found that the willingness to pay on national pride and spirit are depended on gender, occupation, income, and attention to sports. The result shown that national spirit value averagely equals 19.24 baht per month and national pride is averagely 20.22 baht per month.
\end{abstract}

\section{Keywords:}

contingent valuation method, public goods, sport economics

JEL Classification: A10, C49, H41 